\title{
Ultrasound visualization of the left circumflex artery by direct endocardial scanning of the mitral annulus during surgery
}

Tomonobu Abe, MD, Wataru Uchida, MD, Yuji Narita, MD, and Akihiko Usui, MD, Nagoya, Japan

\author{
From the Department of Cardiac Surgery, Nagoya University Graduate School of Medicine, Nagoya, Japan. \\ Disclosures: Authors have nothing to disclose with regard to commercial support. \\ Received for publication June 24, 2016; revisions received July 31, 2016; accepted for publication Aug 18, 2016; \\ available ahead of print Sept 21, 2016. \\ Address for reprints: Tomonobu Abe, MD, Department of Cardiac Surgery, Nagoya University Graduate \\ School of Medicine, 65 Tsurumaicho, Showa-ku, Nagoya, 466-8550, Japan (E-mail: tomonobuabe@med. \\ nagoya-u.ac.jp). \\ J Thorac Cardiovasc Surg 2017;153:53-5 \\ $0022-5223 / \$ 36.00$ \\ Copyright $(2016$ by The American Association for Thoracic Surgery \\ http://dx.doi.org/10.1016/j.jtcvs.2016.08.022
}

\section{PTCS
VIDEO
CLID
......}

Video clip is available online.

The left circumflex coronary artery is susceptible to injury during mitral valve surgery because of its proximity to the mitral annulus. ${ }^{1}$ Recent studies showed that the circumflex artery can be visualized in most patients by transesophageal echocardiography (TEE). ${ }^{2}$ Despite this, prevention of iatrogenic injury seems difficult with this modality. ${ }^{2}$ We describe our experience of visualization of the circumflex artery by direct endocardial scanning of the mitral annulus with a high-frequency ultrasound probe during surgery. This technique may facilitate safe surgery in cases anatomically susceptible to iatrogenic injury.

\section{CLINICAL PRESENTATION}

The patient was a 57-year-old man who had severe mitral regurgitation caused by anterior leaflet prolapse. In the operating room, a transesophageal echo probe (X7-2t transducer, EPIQ 7 ultrasound system; Philips, Amsterdam, The Netherlands) was inserted, and an L-shaped high-frequency linear-array ultrasound probe (L15-7io transducer, EPIQ 7 ultrasound system) was prepared in a clean probe cover on the surgical field for direct epiaortic ultrasound scanning. This procedure was routine.

During prepump evaluation by TEE, the echocardiographer realized that part of the circumflex artery appeared to be running close to the mitral annulus (Figure 1). The surgeons were alerted, and blindly placing sutures for annuloplasty was felt to be dangerous. We had experience in visualizing epicardial coronary arteries using the probe for epiaortic ultrasonography ${ }^{3}$; therefore, we thought it would be possible to visualize the artery by direct scanning of the mitral annulus. We decided to do that before placing

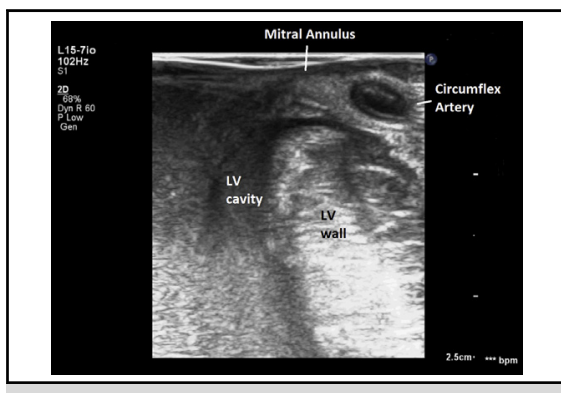

The circumflex artery located by direct scanning of the mitral annulus by an echo probe.

Central Message

The left circumflex artery can be visualized and located by direct scanning of the mitral annulus with an ultrasonographic probe during surgery.

See Editorial Commentary page 55. sutures. The surgery was performed via median sternotomy. After opening the left atrium by left atriotomy, cold saline was infused. The depth was set at $2.5 \mathrm{~cm}$ and the dynamic range was set at $60 \mathrm{~dB}$; the probe was inserted into the left atrium (Figure 2, $A$ ). The mitral annulus was scanned from the anterolateral commissure to $\mathrm{P} 2$, perpendicular to the annulus. The circumflex artery was visualized at higher resolution (Figure 2, B). Identification of the circumflex artery was confirmed by

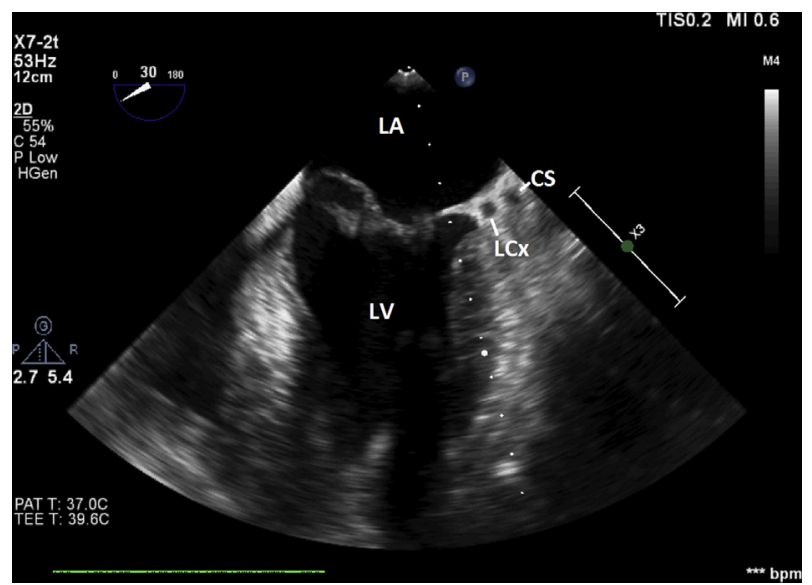

FIGURE 1. Image of intraoperative transesophageal echocardiography before repair. The left circumflex artery runs close to the mitral annulus. $L A$, Left atrium; $C S$, coronary sinus; $L C x$, left circumflex artery; $L V$, left ventricle. 

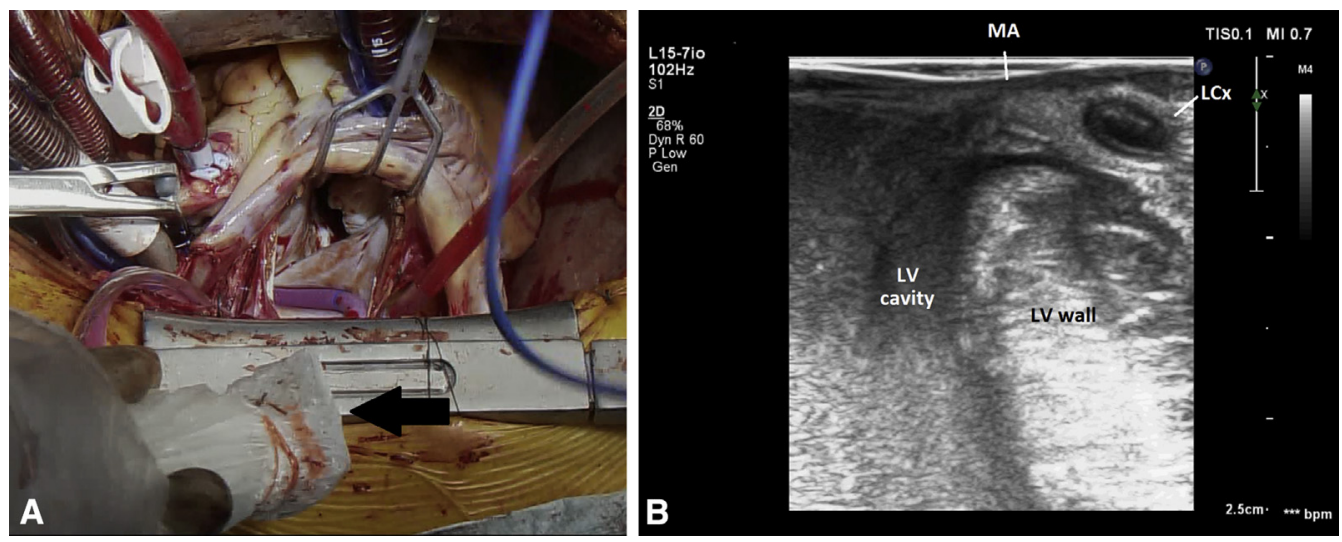

FIGURE 2. A, Intraoperative picture. An L-shaped high-frequency linear-array ultrasound probe (black arrow) was inserted into the left atrium and the mitral annulus was scanned. B, Intraoperative image of endocardial ultrasonography by direct scanning of the mitral annulus. The left circumflex artery is clearly visible. The distance between the mitral annulus and the circumflex artery was $3 \mathrm{~mm}$ at the narrowest point. $M A$, Mitral annulus; $L C x$, left circumflex artery; $L V$, left ventricular cavity; $L V$ wall, left ventricular wall.

administering an additional dose of cardioplegia from the aortic root. The left ventricular cavity was identified as a cavity filled with fluid. The posterior mitral valve leaflet was identified as a floating thin structure (Video 1). The mitral annulus was identified as that part of the mitral leaflet attached to the left ventricular myocardium. We measured the distance between the artery and the mitral annulus. The distance at the narrowest point was $3 \mathrm{~mm}$; thus, we believed that annuloplasty could be performed safely if the sutures were carefully placed.

The mitral valve was repaired by chordal replacement to the anterior leaflet and ring annuloplasty with a semirigid ring (Physio 2; Edwards Lifesciences, Irvine, Calif). For ring implantation, 2-0 mattress sutures were carefully

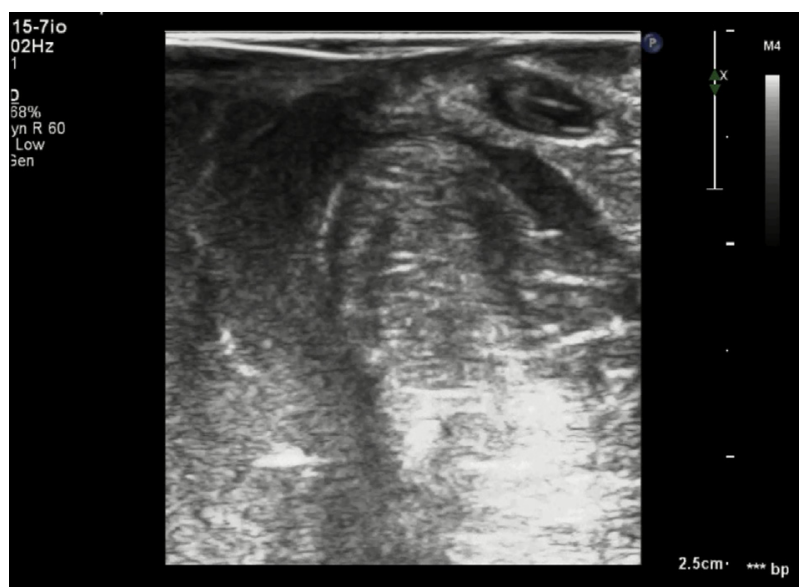

VIDEO 1. An intraoperative video clip showing direct endocardial ultrasonography of the mitral annulus. The posterior mitral leaflet is the floating structure in the left ventricular cavity. Video available at: http://www.jtcvsonline. org/article/S0022-5223(16)31046-7/addons. placed at the mitral annulus where the circumflex artery was close. Special care was taken to place the needle perpendicular to the atrial surface toward the left ventricular apex. Subsequently, the patient had no clinical problems and postrepair TEE evaluation revealed the circumflex artery to be intact.

\section{DISCUSSION}

The left circumflex coronary artery is susceptible to injury during mitral valve surgery. ${ }^{1}$ The risk of it being damaged during the Cox maze procedure has been pointed out. ${ }^{4}$ Ender et $\mathrm{al}^{2}$ reported that the circumflex artery could be visualized in $99 \%$ of patients by TEE. Although TEE was useful for early detection of injury in patients undergoing mitral valve repair, iatrogenic injury was reported in 3 of 110 patients, suggesting that injury prevention was difficult even when using TEE.

We have successfully visualized the left circumflex artery by direct endocardial scanning of the mitral annulus in patients in whom TEE showed the circumflex artery to lie in close proximity to the annulus. Uncomplicated mitral valve repair was completed. Images of higher resolution can be obtained by this method than by TEE, and the artery can be located while directly observing the position of the ultrasonographic probe on the mitral annulus. This technique may be helpful to facilitate safe surgery in patients susceptible to iatrogenic injury at the time of mitral valve surgery and the Cox maze procedure. We are now conducting a feasibility study to confirm the reproducibility of this technique. One limitation of this technique is a definite learning curve, which we became aware of as we gained practical experience.

To the best of our knowledge, this is the first report of ultrasound visualization of the circumflex artery by direct endocardial scanning of the mitral annulus. 


\section{CONCLUSIONS}

We describe ultrasound visualization of the left circumflex artery by direct endocardial scanning of the mitral annulus during surgery.

\section{References}

1. Grande AM, Fiore A, Massetti M, Vigano M. Iatrogenic circumflex coronary lesion in mitral valve surgery: case report and review of the literature. Tex Heart Inst J. 2008;35:179-83.
2. Ender J, Selbach M, Borger MA, Krohmer E, Falk V, Kaisers UX, et al. Echocardiographic identification of iatrogenic injury of the circumflex artery during minimally invasive mitral valve repair. Ann Thorac Surg. 2010;89:1866-72.

3. Suematsu Y, Takamoto S, Ohtsuka T. Intraoperative echocardiographic imaging of coronary arteries and graft anastomoses during coronary artery bypass grafting without cardiopulmonary bypass. J Thorac Cardiovasc Surg. 2001;122: $1147-54$

4. Castella M, Garcia-Valentin A, Pereda D, Colli A, Martinez A, Martinez D, et al Anatomic aspects of the atrioventricular junction influencing radiofrequency Cox maze IV procedures. J Thorac Cardiovasc Surg. 2008;136:419-23.

\title{
EDITORIAL COMMENTARY
}

\section{Intraoperative endocardial ultrasonography: Improving safety in mitral valve surgery}

\author{
Juan A. Crestanello, MD
}

From the Division of Cardiac Surgery, Wexner Medical Center, The Ohio State University, Columbus, Ohio. Disclosures: Author has nothing to disclose with regard to commercial support.

Received for publication Sept 5, 2016; accepted for publication Sept 6, 2016; available ahead of print Oct 7, 2016. Address for reprints: Juan A. Crestanello, MD, Division of Cardiac Surgery, Wexner Medical Center, N-820 Doan Hall, 410 W 10th Ave, Columbus, OH 43210 (E-mail: juan.crestanello@osumc.edu). J Thorac Cardiovasc Surg 2017;153:55-6 $0022-5223 / \$ 36.00$

Copyright (C) 2016 by The American Association for Thoracic Surgery http://dx.doi.org/10.1016/j.jtcvs.2016.09.002

Injury to the circumflex coronary artery during mitral valve surgery is a dangerous but fortunately rare complication of mitral valve surgery. ${ }^{1}$ The circumflex coronary artery courses in proximity to the mitral valve annulus and is therefore at risk for injury during mitral valve surgery. Anatomic and computed tomographic studies have demonstrated that the distance between the annulus and the artery ranges from $0.4 \pm 3.6$ to $4.8 \pm 3.6 \mathrm{~mm}$, with the closest point being in the posterior annulus near the anterolateral commissure, which is the most common site of injury (Figure 1). ${ }^{2}$

Injury to the circumflex artery occurs more commonly in patients with left dominant coronary circulation. The mechanisms of injury include (1) direct injury by either encircling or transfixing the artery, (2) vascular distortion secondary to changes in annular size or shape, and (3) external compression. Such injury may lead to complete or partial arterial occlusion, kinking, or spasm.

Prevention of this complication includes the identification of the course of the circumflex artery in the preoperative coronary angiogram and in the intraoperative transesophageal echocardiogram and the correct placement of annular sutures. Multidetector computed tomography, although not routinely done, may be very useful.

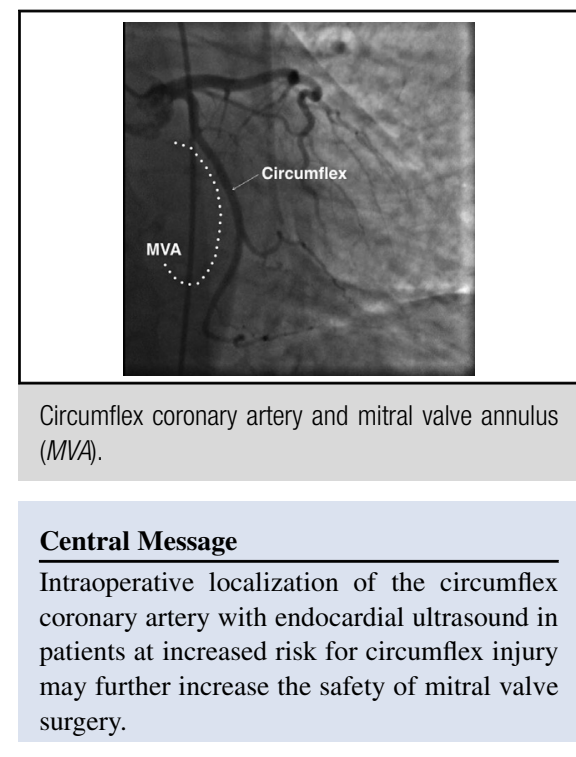

See Article page 53.

In this issue of the Journal, Abe and colleagues ${ }^{3}$ describe the use of endocardial ultrasonographic scanning of the posterior mitral valve annulus to identify the location of the circumflex artery and its distance from the annulus. This is done with an epicardial ultrasound probe, which is readily available in most operating rooms and with which most surgeons are familiar. Minimal additional training thus would be required to scan the mitral annulus searching for the circumflex coronary artery; however, the identification of the artery in the arrested and empty heart without coronary flow may not be always easy. 